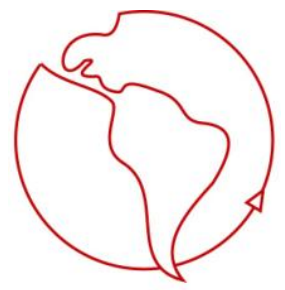

\title{
Contradicción, Complementariedad e Hibridación en las Relaciones entre lo
} Rural y lo Urbano

Marlon Javier Méndez Sastoque

Universidad de Caldas, Manizales, Colombia

marlon.mendez@ucaldas.edu.co

\section{Resumen}

El propósito de este artículo es dar una mirada crítica a las relaciones entre lo rural y lo urbano, a la luz de lo hoy entendido como nueva ruralidad. La discusión se plantea en torno a tres ejes temáticos: 1) el papel de lo urbano como componente protagónico del nuevo concepto de lo rural; 2) la tendencia a la conformación de figuras híbridas rural-urbanas; y 3) el surgimiento de nuevas relaciones de conflicto ligadas a la expansión física de la ciudad sobre el campo. Se finaliza con algunas reflexiones acerca de la forma en que se abordó el problema, enfatizando la necesidad de entender lo rural como un concepto en construcción permanente.

Palabras claves: nueva ruralidad, relaciones campo-ciudad, articulación rural-urbana, pluriactividad rural, sociología rural.

\section{Summary}

The purpose of this article is to give a critical view of the relations between rural and urban realms under the light of what is called "new rurality". The discussion is posed around three thematic axes: 1) the role of the urban realm as a central component of the new concept of rurality; 2) the tendency for conforming hybrid rural-urban figures; and 3) the rise of new conflictive relations linked to the physical expansion of cities over the country. Some reflections on the ways in which the problem was approached, with emphasis on the need to understand rurality as a concept in permanent construction are given at the end.

Key words: new rurality, city-country relations, rural-urban articulation, rural pluriactivity rural sociology.

\section{Introducción}

Asumir lo rural como una categoría dinámica implica repensar sus límites y elementos esenciales, reconociéndolo como parte de un todo. Omitiendo matices y especificidades de enfoque, podemos plantear que es precisamente este lineamiento el que guía el avance hacia la construcción teórica de una nueva noción de lo rural. Aunque hoy pueda asumirse como un presupuesto implícito, vale traer a colación, que lo rural no se reduce a una simple categorización del uso del espacio, sino que incluye y realza como protagonistas a los actores que lo habitan, es decir, a quienes lo construyen y aprehenden como su propia realidad en el devenir cotidiano de sus vidas.

Comulgando con lo anterior, el objetivo de este ensayo es dar una mirada crítica a las nuevas formas de concebir lo rural enfatizando sobre una de sus principales aristas: la articulación entre lo rural y lo urbano como elemento detonante de cambio y reajuste. Para cumplir con el objetivo propuesto se desarrollaran tres ejes principales: 1) la inclusión paulatina de lo urbano como componente esencial de una nueva noción de lo rural; 2) la construcción de formas híbridas rural-urbanas; y 3) el redistanciamiento conflictivo entre estas dos categorías como una nueva forma de relación. 
El primer eje atiende al interés por reconocer cómo lo urbano empieza a ganar espacio en la redefinición de lo rural, hecho que se expresa en situaciones como la pérdida de protagonismo de la actividad agrícola como elemento distintivo de la dinámica rural, dando paso a la inclusión del trabajo no-agrícola y urbano, como práctica indispensable para la recomposición de la unidad productiva familiar. En esta misma vía, la adopción de una óptica territorial en donde el campo y sus ciudades son visualizados como elementos interdependientes y en interacción continua, refuerza el planteamiento defendido; postura que sumada a la primera, sugieren el abandono paulatino de la tradicional definición de lo rural por oposición a lo urbano.

El segundo obedece a la intención de explorar cómo el acercamiento y la facilidad de desplazamiento continuo entre lo rural y lo urbano, asumidos ahora prácticas cotidianas por los habitantes rurales, permite la apertura hacia nuevas formas de concebir la realidad. Esta reflexión mantendrá un matiz teórico, haciendo una lectura del fenómeno tomando como marco referencial la propuesta de Peter Berger y Thomas Luckmann sintetizada en su obra La construcción social de la realidad (1979).

Aunque lo descrito anteriormente resalta el carácter "armónico" del acercamiento entre lo rural y lo urbano, es necesario aludir también a su contraparte "conflictiva". ¿Qué ocurre cuando de la articulación se pasa a la absorción física de lo rural por lo urbano? ¿Cuál es la respuesta de los actores rurales ante la inminente amenaza contra su espacio vital? Es justamente a esta preocupación a lo que atiende el tercer eje temático propuesto.

Se espera que este documento proporcione una mirada conjunta del problema, que sirva de base para el tránsito de la teoría a la práctica, al constituirse como marco de referencia para la posterior aproximación al fenómeno mediante la inmersión en una situación real y concreta.

\section{Lo Urbano en lo Rural}

Abordar el tema de lo urbano en lo rural implica el reconocimiento de múltiples elementos en relación. Para empezar es necesario develar la intima fusión establecida entre ruralidad y agricultura, elementos históricamente conjugados, sobre cuya separación comienza a evidenciarse el cambio en la noción de lo rural. En esta misma vía de cambio, la cada vez más cercana relación entre lo rural y lo urbano tiende a superar antiguas contradicciones. La oposición entre campo y ciudad, igual que la establecida entre lo rural y lo urbano, comienza a desvanecerse. En este sentido, el reconocimiento de complementariedades, aunque no siempre equilibradas, comienza a ganar espacio sobre la simple diferenciación. Este deambular entre relaciones estrechas nos lleva, finalmente, al planteamiento de figuras híbridas entre lo rural y lo urbano, siendo la descripción de este proceso el propósito del presente apartado.

\subsection{Agricultura, ruralidad y urbanidad}

La interacción tradicional entre lo rural y lo urbano se ha fundamentado en la provisión en doble vía de bienes y servicios. En esta dinámica, la especialización de lo rural en la actividad agrícola ha definido su participación. Mientras el campo provee a la ciudad de alimentos y materias primas, la ciudad ofrece de los habitantes del campo toda una gama de bienes y servicios. En esta relación de complementariedad, las carencias de uno son suplidas por el otro. No obstante, ante la crisis ambiental del modelo urbano, a la función tradicional de abasto cumplida por lo rural se suman nuevas funciones que involucran directamente el uso de los recursos naturales. Ante este contexto, la relación entre agricultura, urbanidad y ruralidad oscila entre la especialización distintiva, la articulación y la refuncionalización, tópicos que guiarán la siguiente discusión. 


\subsubsection{Agricultura y ruralidad}

Desde los inicios de la organización social del hombre, la agricultura aparece como el elemento que le permitió a las poblaciones pasar de su condición de nómada a una sedentaria. Tal como lo mencionan Echeverri y Ribero (2002:30), es precisamente en dicho proceso de sedentarización donde se halla el origen de la configuración territorial. Siguiendo lo dicho podemos plantear que la agricultura no es sólo responsable de haber provisto los elementos necesarios para la supervivencia de estos grupos, sino que, adicionalmente, determinó su localización y las características y condiciones de su desarrollo social e institucional.

La lógica contenida en esta idea nos da respuesta al por qué de la inseparabilidad entre ruralidad y agricultura. Así, al dar cuenta de lo rural, desde las definiciones más desprevenidas y espontáneas, hasta aquellas más elaboradas y dotadas de una pretensión científica, hacen referencia a esta estrecha relación. A continuación exploraremos cada punto de vista:

Jiménez (1998:6) plantea que si hacemos el ejercicio de preguntar a la gente del común que es lo rural, muy probablemente encontraríamos respuestas como las siguientes: lo rural es el campo, la agricultura, el mundo de los campesinos. Aquí lo rural es definido por asociación a aquellos elementos más visibles del entorno: localización, actividad económica y actores sociales; en donde, tal como lo resalta el autor, los términos campo, mundo campesino, agricultura y rural, son usados como sinónimos, revelando, a través del lenguaje, la inseparabilidad percibida entre agricultura, ruralidad y sociedades rurales.

Por el lado de los especialistas, Sorokin y Zimmermann (1929:15) definen sociedad rural como aquella en la cual los individuos activamente ocupados lo están en labores agrícolas. De manera similar, Pickenhayn (1982:37) define hábitat rural como "una forma generalizada de ocupación del espacio, ligada específicamente a la explotación de recursos naturales". En comunión con los autores precedentes, Bejarano (1998:34) define lo rural como "la territorización de lo agrícola"; en esta misma vía, para Echeverri (1998:16-17) lo rural corresponde al territorio que se ha estructurado y conformado a partir de las actividades económicas primarias, es decir, aquellas que implican el aprovechamiento de la tierra para su producción.

En cada caso salta a la vista la íntima cercanía entre ruralidad y agricultura, hecho que nos remite a su origen común. De esta manera, aunque hoy reconozcamos que lo rural es mucho más que lo agrícola, no debemos dejar de lado que lo agrícola sigue y seguirá siendo el fundamento de lo rural. Siguiendo esta lógica, todo cambio suscitado en lo rural será sobre su base agrícola.

Lo anterior nos sirve para aceptar con más mesura la analogía frecuentemente establecida entre agricultura y ruralidad, a pesar de los aires de cambio. No obstante, cuando aceptamos que lo rural es más que lo agrícola, no es raro que salte a nuestra mente la relación con lo urbano. Si lo rural es lo agrícola, lo noagrícola ha de ser lo urbano. Pero, si lo rural y lo urbano han sido tradicionalmente definidos por oposición, ¿cómo enfrentar este nuevo dilema? Dar respuesta a esta pregunta nos lleva a plantearnos otras: ¿Cuál es el punto de ruptura entre estas dos categorías?, ¿qué tan distante se encuentra la una de la otra? De esto nos ocuparemos a continuación.

\subsubsection{Distinción entre rural y urbano}

Comprender la distinción entre lo rural y lo urbano implica que nos remontemos a su origen común. Como en cualquier proceso morfológico esta distinción comprende dos pasos esenciales: diferenciación y especialización. Una vez superadas estas primeras etapas, lo que sigue es el ajuste a una misma estructura. Aunque las partes son y cumplen funciones diferentes no dejan de integrar un mismo todo. Así, las 
carencias identificadas en una son suplidas con lo aportado por la otra. A continuación aplicaremos este esquema a las relaciones entre lo rural y lo urbano.

\subsubsection{Origen de la diferenciación entre campo y ciudad}

Si nos remontamos al pasado, para el hombre medieval una discusión acerca de lo rural y lo urbano resultaría irrelevante. En dicha época, aunque las ciudades ya existían, tan solo una parte poco significativa de la población habitaba en ellas. Las personas cultivan el sustento de su propia comunidad feudal llevando una vida que hoy clasificaríamos como "rural", aunque para ellos, en su momento, esto no tuviera ninguna importancia (Siquiera y Osorio 2000:72). En aquella época las ciudades eran sobre todo puntos donde se localizaban los santuarios, donde tenía lugar el intercambio de mercancías, en pocas palabras, centros comerciales y administrativos.

Esa concentración de actividades antes dispersas dio pie al surgimiento de lo que hoy podríamos llamar proto-ciudades: al interior de las murallas se concentraron los santuarios, la fuente, la aldea, el mercado. En este contexto, las ciudades comenzaron a ganar importancia en el proceso de transito hacia el capitalismo. Era, en tanto, un capitalismo esencialmente comercial, aunque todavía la población era mayoritariamente "rural".

Con la revolución industrial y el ascenso del capitalismo sobrevino un acelerado proceso de migración de la población hacia las ciudades, dando a la producción el papel de principal fuente de acumulación de capital, puesto antes ocupado por la comercialización. No obstante, como menciona Marx en El Capital, en los principios de la industrialización, la técnica aun no había producido los medios suficientes para proporcionar las fuerzas capaces de dar movimiento a las máquinas y, así, las industrias tenían que ser instaladas no en las ciudades, sino en aquellas áreas en donde las fuerzas motrices de origen animal o natural (molinos de viento, las ruedas de agua) estuviesen disponibles, o sea, en el campo. Sin embargo, con la invención de la máquina a vapor la fuerza motriz fue doblegada, tornándose la industria independiente del campo, pudiéndose instalar en los centros urbanos (Siquiera y Osorio 2000:73).

Lo que nos interesa ver aquí es que cuando esto ocurre, se consolida la separación entre campo y ciudad. Mientras el campo se especializa en la producción primaria, la producción secundaria fue trasladada en su mayor parte a las ciudades. En este sentido, podríamos señalar que el surgimiento de la distinción entre lo rural y lo urbano tiene su origen en la diferenciación entre el campo y la ciudad; diferenciación que se fundamenta en la especialización productiva. Así, cuando la industria abandona el campo, la ciudad se especializa en la producción industrial, mientras el campo continúa con su labor tradicional.

Pero, si cada una de las partes asumió simplemente una función específica como contribución al engranaje productivo general, ¿por qué la tendencia a definirlas por contraste y no como complementarias? De esto nos ocuparemos en el siguiente apartado.

\subsubsection{Lo rural como opuesto y complementario a lo urbano}

Con la especialización agrícola del campo, sus habitantes se vieron avocados a recurrir cada vez más a la ciudad en demanda de bienes y todo tipo de respuestas a sus necesidades. Cabe anotar que lo único que se concentró en las ciudades no fue la industria, sino también la oferta de una diversa gama de productos y servicios. Mientras el campo se especializó y asumió la función de producción alimentos y materias básicas para la industria; la ciudad tuvo que responder a las demandas de una población urbana en crecimiento, ahora también concentrada en ella. No obstante, la ciudad no sólo tuvo que dar respuesta a las demandas de la población urbana, sino que además tuvo que atender a las de la población rural. . 
Es en este contexto donde lo rural puede ser definido como opuesto a lo urbano. Todo aquello de lo que carece el campo se encuentra concentrado en la ciudad. Pero, ¿cuáles son esas carencias?

Siguiendo lo expuesto por Paniagua (1998:252), "la ciudad se ha convertido en la creación humana donde el hombre se cohesiona y se organiza en armonía, abandonando el aislamiento y la dureza de la vida del campo, por más que allí la naturaleza esté al alcance de la mano”. Según este planteamiento, es en el ambiente urbano donde la humanidad logra mejorar, mitigar y superar, aunque no totalmente, algunos de los más severos azotes de la existencia. Las economías de aglomeración allí radicadas, que no son sólo para la vida productiva, hacen factible la concentración y abaratamiento de los servicios que acercan al individuo a la educación, la salud, la vivienda y el esparcimiento.

El mismo autor continúa diciendo que más que un simple lugar para vivir, el mundo urbano es el motor del desarrollo económico, social y científico; el promotor de la expansión de las artes y letras, de la información y del conocimiento. Es también el terreno en donde se han producido y se producen las innovaciones tecnológicas, donde la investigación y sus aplicaciones en beneficio de la humanidad encuentran las condiciones más propicias. Así, por congregar a un número de personas en un mismo y reducido territorio, la ciudad es, además, asiento de la producción y consumo de bienes y servicios de diversa índole.

La anterior lectura nos da una clara respuesta a la pregunta planteada. No obstante, es importante reconocer que se trata de una lectura urbana de lo rural, desde donde, igualmente, se puede realizar una contralectura. Para muchos la ciudad congrega los mayores males que encuentra la civilización: multitud humana anónima, contaminación ambiental, marginalidad social, tugurización, delincuencia. Aludiendo a lo expuesto por Rello (1998:233), y asumiendo una postura algo romántica, la ciudad puede ser vista como "el desagradable paisaje de concreto y acero opuesto a la tibia belleza del panorama campestre".

Siguiendo con lo anterior, Gutiérrez (1988:186-198) menciona que debido a las condiciones contradictorias en que ha evolucionado la ciudad, se han generado agudos problemas sociales que se manifiestan en el espacio y alteran su funcionamiento: déficit de servicios públicos (acueducto, alcantarillado, energía, aseo); déficit de vivienda; déficit de transporte por el crecimiento desordenado de la ciudad; déficit en la prestación de servicios de salud, educación y recreación; inseguridad, desempleo y congestión en algunas zonas que han llegado a concentrar numerosas actividades, haciendo de ellas áreas sobreutilizadas de difícil circulación y creciente deterioro. Ante esta situación, el retorno a lo rural sería una salida decorosa.

Es importante considerar que la definición por contraste puede llevarnos a la idealización de cualquiera de los dos órdenes de estudio. Así, si se idealiza lo rural, se sataniza lo urbano, y viceversa. No obstante, esta opción metodológica suele ser la más común.

Siguiendo lo dicho por Jiménez (1998:6), si hacemos el ejercicio de preguntar a la gente del común qué es lo rural, muy probablemente encontraríamos respuestas como las siguientes: lo rural es el mundo tradicional, donde hay pocos habitantes, pero a su vez tranquilidad y vida placentera. Entre tanto, lo urbano es el mundo civilizado, donde hay todos los servicios, pero a su vez intranquilidad, miedo y contaminación. Caso que nos muestra la tendencia espontánea a definir por oposición, estableciendo categorías antagónicas.

Igualmente, teorías que han servido de soporte a la sociología rural como la del continuo rural-urbano (Sorokin y Zimmerman 1929), presentan la misma debilidad. De acuerdo a Newby (1983:42), este enfoque de la vida rural adolece de una excesiva idealización. Para ilustrar su afirmación, el autor cita un parte de las conclusiones expuestas en la obra Principles of Rural-Urban Sociology: 
"Hasta hace poco, al menos para la mayoría de la población urbana, el ambiente de la ciudad ha sido mucho menos natural y ha brindado menos oportunidades que el ambiente rural para satisfacer las necesidades humanas básicas y sus impulsos fundamentales... ¿Puede satisfacer un ambiente urbano y su estilo de vida los impulsos y hábitos fundamentales del hombre? La respuesta es no. Ni los impulsos hacia una actividad creativa; ni el deseo vehemente de diversidad y aventura; ni la necesidad fisiológica y psicológica de aire fresco, de disfrutar con los propios ojos del verde de los campos y de oír el canto de los pájaros, pueden ser satisfechos. De estos y de miles de fenómenos similares se han privado el hombre urbano... A pesar de las enormes mejoras en las condiciones de vida, la ciudad aún sigue conservando un gran número de elementos antinaturales a través de los cuales se estimula el descontento y los desórdenes (Sorokin y Zimmerman 1929:466).”

El ejemplo anterior refuerza lo dicho. La tendencia a definir por contraste ahonda la separación entre ambas categorías. Las carencias de una se encuentran concentradas en la otra, pareciendo esta discusión de nunca acabar. No obstante, si ambas forman parte de un todo, si no hay forma de aislarlas por completo, ¿cómo mediar entre lo rural y lo urbano?, o mejor aun, ¿cuáles han sido los puntos de encuentro entre estas dos categorías? De esta manera, luego de haber transitado por las contradicciones, continuaremos con las complementariedades.

\subsubsection{Articulación funcional entre lo rural y lo urbano}

A la luz de la nueva ruralidad hoy es posible evidenciar que la articulación entre lo rural y lo urbano muestra dos facetas diferenciables. La primera corresponde a la articulación tradicional fundamentada en el intercambio de bienes y servicios; la segunda alude a las nuevas funciones otorgadas a lo rural como respuesta a la crisis ambiental urbana. A continuación nos ocuparemos de ellas.

\subsubsection{Articulación tradicional}

El campo provee a la ciudad alimentos, materias primas y fuerza de trabajo sobrante. La ciudad provee al campo insumos, productos industrializados, espacios para la comercialización, servicios educativos, recreativos, institucionales, de salud, entre otros. De esta manera, lo urbano y lo rural se complementan en la medida en que cada parte pone a disposición de la otra los elementos necesarios para suplir sus carencias. A este tipo de relación plenamente reconocida podemos darle el nombre de articulación tradicional.

Pero, si hablamos de complementariedad, ¿existe realmente un equilibrio en el aporte realizado por cada una de las partes?

Podríamos plantear que en esta doble vía, el excedente económico generado en las zonas rurales contribuye a la dinamización de las ciudades o áreas urbanas vecinas, a través de la demanda de bienes y servicios. No obstante, es importante aclarar que el papel dinamizador del campo se expresa con más intensidad en aquellas regiones de vocación agrícola, en donde las ciudades mantienen lazos de mayor dependencia con las zonas rurales circundantes. Como menciona Rello (1998:242), en ciudades de vocación industrial, comercial, minera o de servicios, las cuales dependen poco de los ingresos de la agricultura, el progreso urbano puede coexistir con un atraso del campo; situación que creará incentivos para la migración rural-urbana, el crecimiento urbano y el paulatino despoblamiento del campo.

Muy acorde con lo anterior, Linck (2000:79) señala que las áreas rurales más próximas a las ciudades dejan de cumplir funciones de abasto relevantes. Aunque la producción agrícola no desaparece del todo, el 
suministro de víveres en lo esencial depende de cuencas productivas lejanas. Ante este panorama, ¿cuál ha de ser el devenir de los habitantes de las áreas de intersección entre el campo y la ciudad? Si hay una ruptura en el proceso de articulación tradicional, ¿de qué manera ha de relacionares ahora lo rural con lo urbano? La búsqueda de respuesta a estos interrogantes nos ubica ante el tema de las nuevas funciones urbanas de lo rural.

\subsubsection{Nuevas funciones urbanas de lo rural}

Nuevos valores sustentan la búsqueda citadina de la proximidad con la naturaleza y la vida en el campo.

Debido a la degradación de las condiciones de vida en las grandes urbes, la sociedad fundada bajo el esquema urbano-industrial empieza a ser cuestionada. Como menciona Carneiro (1998), el aire puro, la simplicidad de la vida y la naturaleza son vistos como elementos purificadores del cuerpo y el espíritu contaminados por la sociedad industrial. En este marco, el campo pasa a ser reconocido como un espacio de ocio y al mismo tiempo como opción de residencia.

Esa búsqueda de la naturaleza, y el deseo de los citadinos en transformarla en un bien más de consumo, toma la forma de turismo, hecho que llega a transformar el ritmo de vida de las poblaciones rurales. De esta manera son construidos balnearios, posadas, restaurantes, fondas, entre otros, que tienden a sustituir la unidad de producción agrícola, que poco a poco pierde su funcionalidad. Tal como señala Carneiro (1998), esas experiencias, ya conocidas en la realidad europea hace algunas décadas, transforman el campo -como categoría genérica- en un lugar de vida, más que en un espacio de producción agrícola.

De acuerdo a Ramos y Romero (1993:83), autores que escriben desde el contexto europeo, en la actualidad los problemas que afectan a los habitantes urbanos son objeto de atención general y llevan a otorgar nuevas funciones a los espacios rurales que constituyan una vía posible al reequilibrio de las ciudades. Entre las nuevas funciones destacan las siguientes:

* Equilibrio ecológico, en cuanto a conservadores de ecosistemas y a la producción de paisaje de calidad, abierto y natural.

* Producción de agua limpia y conservación de sus fuentes.

* Espacios para actividades de esparcimiento y recreo al aire libre que, cada vez más, están ampliamente demandados por los habitantes urbanos.

* Sumideros de contaminantes del aire, el agua y el suelo.

Aunque es posible que en nuestro contexto encontremos casos que se ajusten a la descripción anterior, tenemos que reconocer que ésta corresponde más al ámbito de los países desarrollados, en donde el retorno a lo rural se experimenta de una manera distinta. En países como los nuestros, el interés sobre lo rural, a pesar de que mantiene un matiz ambientalista, privilegia la conservación y la expansión de lo urbano. Las áreas rurales son consideradas fundamentalmente portadoras de recursos escasos como el agua, los bosques, la biodiversidad, la estabilidad de los componentes del suelo, etc., percibidos como necesarios para el logro de un equilibrio ecológico que permita la sobrevivencia de la ciudad.

Como mencionan Cruz y Moreno (2002:26-27), haciendo referencia al caso de la Ciudad de México, gran parte de los problemas urbanos que consideran a los espacios rurales, están marcados por un discurso ambientalista en el que la preservación y la conservación de las áreas rurales se convierten en las metas a lograr. Se parte de un pronóstico terriblemente desfavorable en el que se cuestiona la sustentabilidad misma de la urbe, en caso de que no se protejan los pocos recursos naturales existentes en las zonas que la circundan. No obstante, al hacer una minuciosa revisión tanto del Programa Metropolitano de Recursos Naturales (1997), como del Programa General de Ordenamiento Ecológico del Distrito Federal (1999), 
las autoras concluyen que ambos se refieren en mayor medida a la conservación del medio natural, dejando de lado lo referente al desarrollo de las comunidades rurales asentadas en las áreas respectivas. De esta manera, aunque se insiste en otorgar nuevas funciones a lo rural, el estímulo otorgado a las comunidades que lo conforman es muy limitado. Parece que se tratara de espacios vacíos.

Por otro lado, mientras se otorga a lo rural la función de amortiguar el desbarajuste ecológico causado por la concentración y la acelerada expansión de la mancha urbana, la ciudad sigue creciendo. Pero, ¿sobre que espacio se extiende la ciudad?, ¿acaso no se extiende sobre el espacio rural?

La expansión de la mancha urbana y la necesidad de contar con suelo urbano para los nuevos pobladores, en su mayoría de bajos ingresos, presiona cada vez más las áreas rurales circundantes. Como mencionan Cruz y Moreno (2002:23), para el caso de la Ciudad de México, la expansión urbana se ha llevado a cabo fundamentalmente a partir de la formación de numerosas colonias populares asentadas sobre áreas rurales denominadas de conservación. Ante este contexto, la función ambiental atribuida a lo rural, entra en contradicción con el mismo proceso de expansión urbana. Igualmente, en la medida en que avanza la edificación, el uso del suelo cambia. Áreas originalmente destinadas a la producción agrícola pierden su funcionalidad productiva al ser convertidas en zonas de residencia.

Ante esta situación, las áreas rurales pierden paulatinamente su función de abasto, viéndose sus habitantes en necesidad de buscar alternativas ocupacionales que reemplacen o complementen a la minimizada producción agrícola. Pero, entonces, ¿qué ocurre con la estrecha relación históricamente establecida entre agricultura y ruralidad?, ¿continúa siendo lo agrícola el fundamento de lo rural? En definitiva, la pérdida de protagonismo de la agricultura como actividad fundamental nos ubica ante el fenómeno de la pluriactividad rural, tema principal del siguiente apartado.

\subsection{Pluriactividad, ruralidad y urbanidad}

Dentro del discurso actual en torno a lo rural, la pluriactividad describe el proceso de emergencia de un conjunto de nuevas actividades que tienen lugar en el medio rural, las cuales pueden ser ejercidas tanto dentro, como fuera de la propiedad campesina, y estar o no relacionadas con la actividad agrícola tradicional. En este sentido, la pluriactividad rural es entendida como una de las más significativas expresiones de lo que hoy denominamos nueva ruralidad.

Sin desconocer que la agricultura sigue ocupando un lugar destacado, la dedicación a actividades noagrícolas, en principio ampliamente relacionadas con la producción agrícola directa, pasa a ocupar un lugar estratégico en la reproducción de las unidades familiares. Igualmente, en el contexto definido por la incursión en lo no-agrícola, la articulación entre lo rural y lo urbano empieza a generar nuevas relaciones que se suman a las tradicionales. La participación rural en el mercado de trabajo urbano es el factor que se hace más visible.

No obstante, aunque exista consenso sobre lo anterior, aun queda por responder una pregunta clave: ¿cómo se expresa el fenómeno en la práctica? Dar respuesta a este cuestionamiento nos lleva a contemplar la forma como lo rural y lo urbano se conjugan en la búsqueda de alternativas a la pérdida de la funcionalidad agrícola. Para cumplir este propósito proponemos la exploración de dos categorías básicas: la ocupación rural urbanizada y la ocupación rural urbana. A continuación expondremos cada una de ellas.

\subsubsection{Ocupación rural urbanizada}


Cuando la actividad agrícola pierde la capacidad de ocupar a la totalidad de la fuerza de trabajo familiar, la búsqueda de alternativas ocupacionales es una necesidad apremiante. Al respecto, Schneider (2001) plantea que en la medida en que se libera fuerza de trabajo, esta se incorpora a otros sectores como el comercio y los servicios, dedicándose a un conjunto variado de actividades económicas y productivas, no necesariamente ligadas al cultivo de la tierra, y cada vez menos ejecutadas dentro de la unidad de producción.

No obstante, es necesario agregar que dichas actividades, aunque no estén ligadas al cultivo de la tierra como tal, sí pueden continuar relacionadas con alguna de las fases del ciclo productivo. Parte de los miembros de las unidades familiares encuentran en algunas labores complementarias a la producción directa una fuente alternativa de generación de ingresos. Entre estas podemos señalar la venta de insumos, operación y alquiler de maquinaria, asistencia técnica, mecánica de motores, transporte y comercialización de productos, almacenamiento, manejo de poscosecha.

Aunque las labores anteriormente descritas podrían llegar a ser catalogadas como agrícolas, es necesario hacer una distinción clave. Transitar del escenario de las actividades netamente productivas, es decir, fundamentadas en el conocimiento de las labores particulares de labranza y cultivo, a las directamente relacionadas con el comercio y los servicios complementarios, implica la previa adquisición de una serie de competencias y habilidades específicas indispensables para el ejercicio de los nuevos oficios.

Podemos plantear que este cambio de actividad supone siempre un nuevo aprendizaje. Pero, ¿a dónde recurrir en busca de esas nuevas competencias? La respuesta a esta pregunta nos remite a lo urbano, al ser la ciudad en donde se generan y concentran las distintas posibilidades de capacitación y formación. Así, aunque las nuevas habilidades adquiridas se apliquen directamente en el ámbito rural, su origen es de carácter urbano: de lo urbano se importan nuevos conocimientos que son luego aplicados y ajustados a las particularidades del medio rural. Es en este sentido que podemos hablar de una ocupación rural urbanizada.

Hasta ahora hemos dicho, coincidiendo con autores como Da Silva (1997) y Kageyama (1998), que la pluriactividad rural tiene generalmente su punto de origen en la misma agricultura. No obstante, si acogemos la premisa de que lo rural es mucho más que lo agrícola, ¿podemos hablar de la existencia de ocupación rural urbanizada no-agrícola?

Al plantear la oposición entre campo y ciudad resaltamos que las carencias de lo rural eran suplidas recurriendo a lo urbano. Sin embargo, la movilización del campo a la ciudad para suplir toda carencia no es el único camino a seguir. En la medida en que la actividad agrícola deja de ocupar la totalidad de los miembros de la familia, algunos de ellos optan por ofrecer en el campo bienes y servicios antes sólo ofertados en el medio urbano. Atendiendo a esta lógica es posible ver como habitantes rurales se ocupan en actividades no-agrícolas sin que esto implique su mudanza a la ciudad.

Así, remitiéndonos a la práctica, hoy encontramos en el campo enfermeras, promotores de salud, docentes, electricistas, plomeros, constructores, panaderos, costureras, tenderos, dueños y administradores de papelerías, bares, droguerías, billares, etc., ejerciendo su labor en el ámbito rural. Y aunque esto no es reciente, lo inédito es que hoy reconocemos con mayor nitidez la presencia de nuevos actores en el campo. $\mathrm{Si}$ antes, acostumbrados a homologar lo agrícola a lo rural sólo veíamos en él campesinos y agricultores, hoy advertimos su heterogeneidad ocupacional. A los oficios no-agrícolas habituales se suman otros menos tradicionales, que demanda la apropiación de nuevos conocimientos; saberes, en muchos casos, adquiridos en el entorno urbano. 
Recapitulando, podemos argumentar que la ocupación rural urbanizada no sólo se centra en lo agrícola, sino que se extiende sobre todo aquello que es indispensable para la vida en el campo. Pues, ¿acaso las necesidades de los habitantes rurales no son casi las mismas que las de los habitantes urbanos?

No obstante, aun queda una cuestión por resolver: ¿Es siempre el ámbito rural un escenario propicio para el desarrollo de labores alternativas? ¿Qué ocurre cuando una nueva ocupación implica la mudanza de los habitantes del campo a la ciudad? Dar respuesta a esta pregunta nos lleva a plantear la existencia de un tipo de ocupación rural urbana.

\subsubsection{Ocupación rural urbana}

En la medida en que la agricultura deja de cumplir la función de ocupar la totalidad de la fuerza de trabajo familiar, cada vez más habitantes rurales ven la necesidad de acceder al mercado de trabajo urbano. No obstante, al llegar a la ciudad, no encuentran en ella una economía formal en condiciones de acogerlos. Esta circunstancia los obliga a definir estrategias de sobrevivencia que les permita sobreponerse a la adversidad. Ante esta circunstancia, los nuevos habitantes de la ciudad llevan a cabo actividades complementarias y subsidiarias de los sectores informales de la economía, tales como: acopio de materias primas (reciclaje), comercio informal, producción artesanal y prestación de servicios varios (vigilancia, servicio doméstico, jardinería, arreglos locativos, etc.), entre otros.

De acuerdo con Henao (1991:72), las actividades realizadas por los migrantes rurales en muchos casos reproducen las características de la economía campesina. Si bien pueden estar ligadas al mercado, lo fundamental es la reproducción de la unidad económica sustentada en el trabajo familiar, siendo su eje la subsistencia y las estrategias de supervivencia en grupo. El mismo autor señala que la incursión en este tipo de labores carece de rigor en los cálculos costo/beneficio y que los salarios no siempre cubren por encima del mínimo necesario para la reposición de la fuerza de trabajo. De esta manera, la incursión rural en el ámbito de la ocupación urbana no alcaza a superar el umbral de la sobrevivencia, por lo que no representa un cambio significativo desde el punto de vista económico.

A lo anterior hay que sumar que en muchas ocasiones el conocimiento acumulado como resultado de la participación cotidiana y continua en las actividades rurales, deja de ser útil en el contexto urbano. Esta situación hace que el migrante rural sea catalogado como ignorante. Así, de ser un productor agrícola, conocedor y experto en su arte, pasa a ser un don nadie, ahora ubicado en el entorno urbano. Este hecho se refleja en el tipo de ocupaciones a las que puede acceder: aquellas que requieren mínima calificación.

Como menciona Mattei (1998:92-115), en el espacio rural empiezan a desarrollarse otras actividades antes típicamente urbanas, como es el caso de la instalación de industrias procesadoras, sistemas de servicios de transporte, comunicación y diversión, entre otras. Sin embargo, el hecho de que estas se instalen en el espacio rural, no hace que adquieran un carácter rural. Se trata simplemente de la ubicación de actividades urbanas en el campo, en donde el espacio rural es contemplado como un simple lugar de instalación. Igualmente, debido a su carácter no-agrícola, la vinculación de personal de origen rural sin un previo entrenamiento técnico resulta inoficiosa, a menos que se trate de cargos que requieran mínima calificación.

En otra posible situación, Sacco de Anjos (1995), estudiando la ocupación rural en la ciudad de Massaranduba (Litoral Norte de Santa Catarina, Brasil), expone la figura del campesino-operario, el cual se desplaza todos los días de su residencia en el campo hacia las fábricas de motores en la ciudad de Jaraguá do Soul. Por su parte, las mujeres de esta misma localidad se ocupan en actividades de costura bien sea desplazándose hacia las industrias textiles o trabajando para ellas desde su propia residencia. 
Más allá de lo particular, el caso nos ilustra cómo la ocupación rural urbana puede tener lugar tanto en el mismo espacio rural, como en el exterior. No obstante, independientemente de que se realice dentro o fuera, esta incursión en lo urbano implica siempre una ruptura con la labor agrícola tradicional. Igualmente, la proletarización del campesino significa una pérdida paulatina de su independencia, así como el ajuste a una dinámica económica distinta.

Como hemos podido constatar, independientemente de la forma de articulación entre lo rural y lo urbano, las ciudades vienen siendo reconocidas como parte integrada al espacio cotidianamente configurado por los habitantes del campo. Ante esta circunstancia hablar hoy del campo y sus ciudades no ha de resultar extraño.

\subsection{El campo y sus ciudades}

Para quienes el desplazamiento entre el campo y la ciudad (bien sea en demanda de bienes o servicios, bien debido a su vinculación al mercado de trabajo urbano) se vuelve algo cotidiano, los límites entre lo rural y lo urbano se tornan cada vez más difusos. En este orden, la configuración de su espacio cotidiano integra ambas categorías. Como menciona Santos (1988:70), "el espacio está siempre formado de fijos y flujos, flujos que provienen de esas cosas fijas, y flujos que llegan a esas cosas fijas". Todo este conjunto es el espacio. Fijos y flujos en continua interacción. Para nuestro caso, la movilización entre el campo y la ciudad (fijos sobre los cuales se producen los flujos) sugiere la existencia de un espacio compartido entre lo rural y lo urbano; circunstancia que nos permite hablar del campo y sus ciudades.

Al respecto, Echeverri y Ribero (2002:23) sostienen que los procesos de localización y ubicación poblacional en el espacio, con su consecuente apropiación por parte de los grupos humanos, genera una relación permanente y bidireccional espacio-grupo poblacional que constituye un determinante fundamental en la construcción del territorio.

De esta manera, al hablar de hibridación entre lo rural y lo urbano, debemos tener presente que en el proceso de apropiación del espacio los lugares incorporados corresponde a aquellos que entran a formar parte del desenvolvimiento cotidiano. Así, si lo que conlleva a que un habitante rural se traslade a la ciudad es el acceso al mercado de trabajo urbano, lugares como la fábrica o la empresa donde labora, la plaza o santuario donde vende sus productos, o los barrios donde ofrece su servicio como jardinero, corresponden a aquellos que integra a su vida cotidiana.

No obstante, es importante reconocer que ésta no es la única situación de conjunción rural-urbana. Como ya hemos señalado, existe un tipo de articulación tradicional fundamentada en el intercambio y la complementariedad que no siempre implica un desplazamiento prolongado. Pero, en esta relación entre el campo y sus ciudades, ¿podemos hablar de interdependencia?

Según Rodríguez (1997:78-92), los espacios rurales se transforman en asentamientos que dependen funcionalmente de un núcleo central en donde se localizan actividades terciarias. La centralidad de los núcleos rectores se define tanto a partir de las actividades comerciales, como de los diferentes servicios públicos y privados que se localizan en ellos. Ante esta idea, la centralidad que ejerce cualquier entidad urbana se basa en su capacidad para atraer a los habitantes de su radio inmediato, quienes se desplazan a ella para consumir.

No obstante, aunque los espacios rurales puedan llegar a depender funcionalmente de entidades urbanas, este no es siempre el caso. En regiones de vocación industrial o comercial en donde lo rural, y más aun, la producción agrícola, ocupa un lugar secundario, la centralidad urbana es dominante. Sin embargo, en regiones de vocación agrícola en donde las dinámicas socio-económicas giran en torno a lo rural, la 
situación es distinta. En estos casos, aunque existan centros o núcleos urbanos, la función que cumplen es totalmente rural. La provisión de bienes y servicios tiene como destino la población rural. Así, si existen escuelas y colegios estos han sido creados para atender a una población escolar mayoritariamente rural. Igualmente, si existe un comercio organizado este cobra vida, por ejemplo, cuando en los días de mercado afluye buena parte de la población del campo. En estos casos, estaría bien hablar de "ciudades rurales", es decir, de poblados urbanos inmersos en una dinámica rural; de ciudades que hacen parte de un entramado rural.

Lo dicho cabría dentro de la definición de rural dada por Ceña (1993:52): "lo rural es un conjunto de regiones y zonas con actividades diversas (agricultura, artesanía, pequeñas y medianas industrias, comercio, servicios) en las que se asientan pueblos, pequeñas ciudades y centros regionales, espacios naturales y cultivados". Así, retomando todo lo anterior, podemos plantear que, dentro de la nueva concepción de lo rural, la ciudad puede ser catalogada como una de sus elementos esenciales. Tanto el campo como la ciudad hacen parte del todo rural.

No obstante, es necesario tener en cuenta que lo rural no se remite simplemente a regiones y zonas geográficas. Toda noción de lo rural ha de incluir siempre a sus protagonistas, es decir, a los actores rurales. En este sentido, cada vez que aludimos a la transformación en el ámbito rural estamos refiriéndonos a los cambios experimentados por los habitantes rurales, a la forma en como ellos perciben la alteración de la cotidianidad de sus vidas. Atendiendo a lo anterior, consideramos necesaria la inclusión de una parte dedicada a explorar la forma cómo los sujetos sociales crean su propia realidad, introduciendo cambios derivados de sus nuevas experiencias; siendo las emanadas de la interacción con lo urbano las que queremos enfatizar. En el siguiente capítulo nos ocuparemos de ello.

\section{Desdibujamiento de los límites entre lo rural y lo urbano: una lectura subjetivizante}

El desdibujamiento de los límites entre lo rural y lo urbano alude a los cambios derivados del encuentro cotidiano entre actores representativos de cada parte. El hecho de compartir un mismo mundo sugiere el establecimiento de encuentros "cara a cara". Esta situación, a la vez que permite la distinción, motiva el reconocimiento de elementos comunes. De igual forma, la misma dinámica de interacción propicia la conjunción de escenarios tanto físicos como simbólicos que contribuyen a la construcción de realidades híbridas en la medida en que se estrechan los lazos entre las partes. A continuación aclararemos y ampliaremos lo descrito.

\subsection{Un mundo compartido}

Como se ha señalado hasta el momento, la vida cotidiana de los habitantes rurales sobrepasa los límites de lo rural. Los distintos tipos de articulación con lo urbano han propiciado la configuración de territorios híbridos, noción que nos conduce al reconocimiento de un mundo compartido. En atención a esta primera apreciación, el esquema planteado por Berger y Luckmann en su obra La construcción social de la realidad (1979), promete ser un instrumento útil para la comprensión del fenómeno. A continuación haremos una lectura del problema apoyada en lo dicho por los autores referidos.

La realidad de la vida cotidiana se me presenta como un mundo intersubjetivo, un mundo que comparto con otros. Esta intersubjetividad establece una señalada diferencia entre la vida cotidiana y otras realidades de las que tengo conciencia. En realidad, no puedo existir en la vida cotidiana sin interactuar y comunicarme continuamente con otros. También sé que los otros tienen en este mundo común una perspectiva que no es idéntica a la mía. Mi "aquí" es su "alli". Mi ahora no se superpone del todo con el de ellos. Mis proyectos difieren y hasta pueden entrar en conflicto con el de ellos (Berger y Luckmann, 1979:40-41). 
Para nuestro caso, el mundo compartido es el todo que engloba lo rural y lo urbano. De esta manera, la realidad de la vida cotidiana sobrepasa los límites establecidos entre ambas categorías, sin que esto signifique que haya una superposición total. A pesar de compartir un mismo mundo, este es aprehendido de diferentes maneras. La noción rural de lo urbano es diferente a la noción urbana de lo rural. Así, como ya hemos señalado, mientras para unos el campo y la actividad agrícola da sentido a su existencia, para otros simplemente representa una fuente de recursos alimentarios, ambientales y recreativos.

No obstante, el encuentro entre lo urbano y lo rural permite superar la perspectiva meramente local.

La realidad de la vida cotidiana se organiza alrededor del "aquí" de mi cuerpo y el "ahora" de mi presente. Este "aquí y ahora" es el foco de atención que presto a la realidad cotidiana (Berger y Luckmann, 1979:44).

Cuando para un habitante rural su espacio de desenvolvimiento cotidiano incluye algunas partes de la ciudad, bien sea en atención a la demanda de bienes y servicios o a la vinculación al mercado de trabajo urbano, su "aquí y ahora" es tanto rural como urbano. En esta situación, la comunicación continua con los otros urbanos amplía el campo de interacción social y propicia, a su vez, la apropiación de nuevos objetos significativos. Igualmente, las experiencias significativas resultantes de la interacción son incorporadas al acervo del colectivo, es decir, son difundidas en la sociedad en general, lo cual puede ser visto como una ganancia cultural.

Como plantea Carneiro (1998), las nuevas experiencias engendradas como resultado de los intercambios contribuyen al nacimiento de la diversidad social y cultural en la medida en que la interacción enriquece los acervos culturales y simbólicos, a la vez que amplía la red de relaciones sociales.

Indiscutiblemente, la interacción representa ventajas para las partes. No obstante, es necesario que prestemos atención a la forma en que esta se da. Sí la realidad de la vida cotidiana es algo que comparto con otros, ¿cómo se experimenta a esos otros en la vida cotidiana?

\subsection{La aprehensión del otro}

De acuerdo a Berger y Luckmann (1979:46-47), la experiencia más importante que tengo de los otros se produce en la situación "cara a cara", que es el prototipo de interacción social del que se derivan los demás casos. En esta situación el otro se me presenta en un presente vivido que ambos compartimos. Mi "aquí y ahora" y el suyo, gravitan continuamente uno sobre otro, en cuanto dure la interacción "cara a cara". El resultado es un intercambio continuo entre mi expresividad y la suya.

Sin embargo, es importante aclarar que, a pesar del encuentro frente a frente, siempre aprehendemos al otro por medio de esquemas tipificadores. Estos esquemas son recíprocos, en la medida en que el otro también nos aprende de manera tipificada. De esta manera urbanos y rurales se reconocen mutuamente como: "campesinos" y "citadinos", "provincianos" y "capitalinos", "agricultores" y "funcionarios", etc. En este sentido: yo aprehendo al otro como tipo y ambos interactuamos en una situación que de por sí es típica.

En la medida en que se intensifica el intercambio se hacen más visibles las diferencias existentes y se crean nuevas distinciones. Pasamos así a una situación en donde la no-identidad entre lo rural y lo urbano ahonda la diferencia. No obstante, es necesario señalar que esa misma interacción propicia a su vez la 
identificación de igualdades. En la medida en que el mundo compartido se hace explícito, los estereotipos formados y mantenidos en la distancia empiezan a perder rigidez.

Así, al compartir los mismos escenarios, las partes se identifican tanto en la igualdad como en la diferencia. Esta situación permite experimentar una conciencia de sí en la relación de alteridad con los otros, contribuyendo de esta forma a dar continuidad a la identificación con lo rural. De igual forma, a la vez que permite la diferenciación, esta misma situación permite la identificación de puntos de encuentro, es decir, de necesidades, intereses y preocupaciones comunes.

Carneiro (1998) menciona que las nociones de rural y urbano son representaciones sociales que expresan visiones del mundo y valores de acuerdo con el universo al cual están referidas, estando por tanto sujetas a reelaboraciones y a apropiaciones. De esta manera, si aceptamos la posibilidad de cambio de ambas nociones, cabe que nos preguntemos por las dinámicas que enmarcan dichas transformaciones. En nuestro caso, la creciente interacción entre lo rural y lo urbano constituye el eje central. De esto nos ocuparemos en el siguiente apartado.

\subsection{Mantenimiento y transformación de la realidad social}

La articulación entre lo rural y lo urbano, independientemente de la forma en que se produzca, supone siempre la apertura hacia otras formas de concebir la realidad. En este proceso de exploración, el choque entre lo tradicional y lo nuevo revierte en la instauración de nuevos órdenes, en donde cada una de las partes adopta, adapta e incorpora a lo propio elementos provenientes del intercambio. De esta manera, lo institucionalizado entra en un proceso de transformación que es puesto en evidencia a través del cambio o ampliación del universo simbólico, tema que será desarrollado a continuación.

\subsubsection{Habituación e institucionalización}

Antes de discutir acerca del cambio en el universo simbólico, es necesario que nos detengamos sobre cómo un referente llega a tornarse estable. De acuerdo a Berger y Luckmann (1979:74):

"Toda actividad humana está sujeta a habituación. Todo acto que se repite con frecuencia, crea una pauta que luego suele reproducirse con economía de esfuerzos y que ipso fato es aprendida como pauta por quien la ejecuta. Además, la habituación implica que la acción de que se trata puede volver a ejecutarse en el futuro de la misma manera y con idéntica economía de esfuerzos."

Sustentados en lo anterior, los mismos autores señalan que la habituación es una condición necesaria para la institucionalización. Esta última consiste en una tipificación recíproca de acciones habitualizadas por actores tipificados. En otras palabras, la institucionalización establece que ciertas acciones son realizadas por ciertos actores, construyéndose, de esta forma, las instituciones.

A la luz de nuestro caso, el cumplimiento de la función tradicional de producción y abasto de alimentos y otros bienes para la industria, puede ser interpretado como la forma fundamental de habituación de los sujetos rurales. Las acciones establecidas para los individuos y colectividades rurales han de estar relacionadas con la realización de dicha función. En este contexto, la definición de sociedad rural dada por Sorokin y Zimmermann (1929), refleja el fundamento de su institucionalización: una sociedad rural es aquella en la cual los individuos activamente ocupados lo están en actividades agrícolas. 
Las instituciones comprenden dos aspectos principales: historicidad (las instituciones se crean a través del tiempo y no de una forma instantánea) y control social (las instituciones controlan el comportamiento humano estableciendo pautas de conducta definidos de antemano).

Con relación a lo anterior, en los primeros apartes de este documento hemos mostrado cuál ha sido el camino que ha conducido a lo rural hacia la especialización agrícola. La inseparabilidad entre ruralidad y agricultura, el proceso histórico de diferenciación entre el campo y la ciudad, el origen de la oposición entre lo rural y lo urbano, y la articulación funcional establecida entre ambas categorías, definen, en conjunto, el proceso histórico de institucionalización de lo rural. Por otro lado, su incorporación a la sociedad general está definida por el cumplimiento de su labor específica. Lo rural adquiere sentido sólo en la medida en que cumple con su rol dentro de la sociedad general.

Pero, si esto es lo que ocurre al nivel más general, ¿qué está pasando a nivel del individuo?

La conciencia retiene sólo una parte de la totalidad de las experiencias humanas, porción que una vez retenida se sedimenta como recuerdo. Esas experiencias quedan estereotipadas en el recuerdo como entidades reconocibles y memorables. Si esa sedimentación no se produjese, el individuo no podría hallar sentido a su biografía. Vale decir que la sedimentación no sólo ocurre a nivel individual. También se produce una sedimentación intersubjetiva cuando varios individuos comparten una biografía común, cuyas experiencias se incorporan a un depósito común de conocimiento. No obstante, la sedimentación intersubjetiva sólo puede llamarse verdaderamente social cuando surge la posibilidad de que esas experiencias se transmitan de una generación a otra y de una colectividad a otra.

Acogiéndonos a este marco, podríamos plantear que la parte de la totalidad de las experiencias retenida por los sujetos rurales está siempre en relación con el entorno agrícola. En lo fundamental, sin evocar el cultivo, la cosecha, la siembra, el campo, la parcela, la tierra, la familia, los recursos naturales, ningún actor rural podría hallar sentido a su biografía. De manera similar, desde lo colectivo, la sedimentación intersubjetiva ha de considerar los mismos elementos. La transmisión de estas experiencias de una generación a otra perfilan la construcción de la identidad rural. Igualmente, la transmisión de esa experiencia de una colectividad a otra promueve la distinción, en la medida en que permite el contraste con los otros.

En esta misma vía, la identificación con el espacio instituido como propio acude igualmente a la memoria colectiva. El individuo, la familia y el grupo más amplio son informados por la memoria colectiva heredada de generaciones anteriores. Igualmente, esa misma memoria colectiva informa sobre los cambios adaptativos del grupo, enfatizando sobre las respuestas dadas a los distintos estímulos y obstáculos.

No obstante, a pesar de la continua interacción entre lo rural y lo urbano, la transmisión de las experiencias sedimentadas de una colectividad a otra no es una situación tan cotidiana. Como ya lo señalamos, en los encuentros "cara a cara" la aprensión del otro se da a través de tipificaciones.

Para Berger y Luckmann (1979:97-98) los roles son tipificaciones de lo que se espera de los actores en determinadas situaciones sociales. El individuo, en virtud de los roles que desempeña, ha de penetrar en zonas específicas de conocimiento socialmente objetivado, no sólo en el sentido cognoscitivo, sino también en el reconocimiento de normas, valores y emociones.

En este sentido, lo que se espera de los actores rurales es su identificación y estrecha relación con la agricultura, la tierra, el campo y la naturaleza. Al mismo tiempo, como señalan Galston y Baehler (1995:189), además de relación armónica con la naturaleza, lo que se espera de los actores rurales es la 
prevalencia de relaciones sociales también armónicas, en donde familias e individuos se conozcan íntimamente, se asistan en tiempos de necesidad y confíen los unos en los otros para cooperar en busca de objetivos que no pueden ser atendidos por medio de un esfuerzo solitario. La antítesis es la imagen de la vida urbana como anomia, violentamente competitiva y desprovista del sentido de la ayuda mutua.

En esta misma vía, con relación a la necesidad de asumir roles específicos fundamentados en la división del trabajo, la especialización agrícola es el rol que marca la pauta. De aquí la tendencia espontánea a asociar lo rural con lo agrícola, y más precisamente, a definir a todo actor rural como un productor agrícola.

Pero, en tiempos de avance hacia una nueva noción de lo rural, ¿por qué es tan difícil deshacer esta asociación?

De acuerdo a nuestros autores, el orden institucional se objetiva mediante el proceso de reificación, es decir, mediante la aprensión del orden como si fuera algo no humano, producto de las leyes cósmicas o divinas.

La cuestión decisiva es saber si el hombre conserva la conciencia de que el mundo social, aun objetivado, fue hecho por los hombres, y que estos, por consiguiente, pueden rehacerlo. Para el caso de estudio, la reificación de la condición rural nos ubica ante el problema de la ruptura de un orden históricamente establecido. No obstante, la institucionalización de lo rural, la tipificación de sus actores, las experiencias sedimentadas, así como la especialización agrícola, empiezan hoy a tambalear.

Ante esta situación, lo que nos resta ahora es preguntarnos por el cambio: ¿cuál es el origen del cambio?, ¿cuáles son las fuentes de perturbación?, ¿cómo interpretar ésta situación? De esto nos ocuparemos a continuación.

\subsubsection{Cambios en el universo simbólico}

La continuidad de un orden establecido supone la existencia de diversos mecanismos de legitimación que plantean obstáculos al cambio. Para Berger y Luckmann (1979:135-148), el problema de la legitimación surge cuando las objetivaciones de orden institucional deben transmitirse de una generación a otra. Al llegar a este punto, el carácter autoevidente de las instituciones, ya no puede mantenerse por medio de los propios recuerdos y habituaciones del individuo. La unidad histórica y biográfica se restringe, por lo que hay que restaurarla por medio de explicaciones y justificaciones de los elementos sobresalientes de la tradición institucional.

En este sentido, lo rural asimilado a la territorización de lo agrícola, la articulación funcional entre lo urbano y lo rural, y la subordinación del campo a la ciudad, constituyen los ejes del orden institucionalizado. Por su parte, elementos como el desdibujamiento de los límites entre lo urbano y lo rural, y la aparición de figuras como la ocupación rural urbanizada y la ocupación rural urbana, pueden ser interpretados como perturbadores. Ahora, ante la evidencia de cambio, ¿cómo dar paso a la conformación de un nuevo orden? En la medida en que las nuevas generaciones enfrentan una nueva realidad, la reconstitución de su referente simbólico es una acción prioritaria a seguir. Ante este contexto, la tradición ha de ceder permitiendo la incorporación de los nuevos elementos.

El universo simbólico se concibe como la matriz de todos los significados social y subjetivamente reales. El universo simbólico aporta el orden para la aprehensión subjetiva de la experiencia biográfica. En este sentido, para las nuevas generaciones rurales el universo simbólico supera lo netamente rural dando paso a 
la incorporación de nuevos elementos y significados provenientes del mundo urbano. Su realidad es tanto urbana como rural. De esta manera, una interacción más estrecha con lo urbano permite la ampliación del universo simbólico.

Pero, en un contexto de oposición entre lo rural y lo urbano, ¿implica la ampliación del universo simbólico la ruptura total con lo rural?, o en otras palabras, ¿implica la ruptura con la institucionalización históricamente construida?

La aparición de un universo simbólico alternativo constituye una amenaza en la medida en que su misma existencia demuestra empíricamente que el orden institucionalizado es dudable. No obstante, también en la práctica podemos observar que cambios de hábitos, ideas y costumbres ocurren de manera irregular, con grados y contenidos diversos, más esto no siempre implica una ruptura decisiva con la tradición.

Al respecto, Carneiro (1998) señala que las transformaciones en las comunidades rurales debidas a la intensificación de los intercambios con el mundo urbano (personales, simbólicos, materiales...) no resultan necesariamente en la pérdida de los rasgos distintivos de un sistema social y cultural. Por tanto, no se trata de un proceso inexorable de descaracterización de los núcleos rurales, más sí de una reestructuración a partir de la incorporación de nuevos componentes económicos, culturales y sociales.

Podemos plantear que en el proceso de articulación rural-urbana existe dos posibilidades generales: 1) que el núcleo rural sucumba a las presiones o intereses externos y 2) que se consolide la identidad local. En el primer caso, las perturbaciones sobre la tradición pueden resultar destructivas. En el segundo, la reapropiación de elementos de la cultura rural a partir de una relectura posibilitada por el contacto con lo urbano puede resultar beneficioso. En este sentido, la interacción no se traduce necesariamente en la destrucción de la cultura propia, más sí en la apertura a nuevas posibilidades. Postura que nos lleva a repensar lo rural dentro de un proceso dinámico en continua reconstrucción.

Para Berger y Luckmann (1979:164-184), el individuo no nace miembro de una sociedad: nace con una predisposición hacia la socialidad, y llega a ser miembro de una sociedad. El punto de partida de este proceso lo constituye la internalización: la aprehensión o interpretación inmediata de un acontecimiento objetivo en cuanto expresa significado. No obstante, esta aprehensión no resulta de las creaciones autónomas de significado por los individuos aislados, sino que comienza cuando el individuo asume el mundo en que ya viven otros. El proceso ontogénico por el cual esto se realiza se denomina socialización. Este proceso comprende dos etapas: la socialización primaria y la secundaria.

La socialización primaria es la primera por la que el individuo atraviesa en la niñez; por medio de ella se convierte en miembro de la sociedad. La socialización secundaria es cualquier proceso posterior que induce al individuo ya socializado a nuevos sectores del mundo objetivo de su sociedad.

En general, la socialización secundaria hace referencia a la internalización de sub-mundos institucionalizados. Más específicamente corresponde a la adquisición de roles, estando éstos directa o indirectamente asociados a la división del trabajo, o mejor aun, a la especialización del conocimiento. En este tipo de socialización el sujeto se identifica con un sub-mundo institucional en el cual se incorpora. En la socialización secundaria se capta el mundo social como artificial, no como el mundo natural. En este sentido, la realidad aprendida en el hogar durante la niñez se plantea por sí sola como "natural". En comparación con ella todas las realidades posteriores son artificiales.

Siguiendo el anterior marco, la relación directa con la actividad agrícola, la tierra y la naturaleza hace parte del proceso de socialización primaria, aquel proceso por medio del cual el individuo se convierte en 
miembro de la sociedad rural. Por su parte, el encuentro con lo urbano, mediado por la búsqueda de alternativas ocupacionales, más que por la demanda de bienes y servicios básicos, puede ser interpretado como parte del proceso de socialización secundaria. En este caso, la adquisición de competencias y habilidades específicas indispensable para el ejercicio de nuevas labores, enmarcadas en lo que hemos denominado ocupación rural urbanizada, representan una ruptura con la "naturalidad" de la cotidianidad rural. Igualmente, la incursión en el mercado de trabajo urbano, al implicar un cambio drástico de rol, connota un abandono de las situaciones cotidianas aprehendidas como "naturales".

No obstante, la incorporación en sub-mundos institucionales de origen urbano, como los demarcados por el comercio informal y la prestación de servicios varios, no significa siempre una ruptura total con lo rural, sin que esto signifique que no pueda llegar a presentarse.

Berger y Luckmann (1979:185-204) plantean que la socialización implica la posibilidad de que la realidad subjetiva pueda transformarse. Vivir en sociedad ya comporta un proceso continuo de modificación de la realidad subjetiva, por lo que hablar de cambios implica examinar los diferentes grados de conversión. Así, aunque la realidad subjetiva no pueda ser trastocada totalmente, hay ejemplos de trasgresiones que parecen casi totales si se les compara con otras de menor cuantía. Estas transformaciones son presentadas por los autores como alternaciones.

La alternación requiere procesos de re-socialización primaria. El individuo alternizado se desafilia del mundo anterior y de la estructura de plausibilidad que lo sustentaba, si es posible, corporalmente, o si no, mentalmente. Los interlocutores que intervienen en el diálogo significativo van cambiando, y el diálogo con los otros significantes nuevos transforma la realidad subjetiva. Igualmente deben producirse nuevas interpretaciones particulares de hechos y personas del pasado con significación pasada. Aunque lo ideal sería olvidar por completo, esto resulta muy difícil. Por tanto, lo que se necesita es una re-interpretación del significado de esos hechos y personas de la biografía pasada.

En la re-socialización primaria el pasado se reinterpreta conforme la realidad del presente. No obstante, en la re-socialización secundaria correspondiente, el presente puede interpretarse de modo que se halle en relación continua con el pasado, tendiendo a minimizar aquellas transformaciones que se hayan efectuado realmente.

Así, a pesar de que en la re-socialización primaria se corra siempre el riegos de una desafiliación total con el mundo rural, en el proceso de socialización secundaria el individuo alternizado tiende a encontrar lazos de unión con lo rural minimizando las transformaciones. En este sentido, la fuerza de la inicial socialización primaria se mantiene viva. Por lo tanto, en el nuevo contexto, lo urbano y lo rural se mantienen unidos, forman un entramado de significaciones compartidas que dan lugar a una noción híbrida de realidad.

No obstante, a pesar de nuestro intento por interpretar el problema a partir de las relaciones de comunicación cotidianas, no podemos dejar de lado lo dicho a partir de la arista dominante. En este sentido, es igualmente importante tener en cuenta la postura orientada a la búsqueda de los determinantes estructurales de la articulación rural-urbana. Desde esta perspectiva, y en vía de cubrir lo faltante, cabe que nos planteemos la siguiente pregunta: ¿cuáles han sido las causas estructurales de la incorporación de lo urbano en lo rural? De esto nos ocuparemos en el siguiente capítulo.

\section{Relaciones y mixturas urbano rurales: una lectura objetivizante}


En coincidencia con lo expuesto por Touraine (1997:151), en primera instancia, aprendimos a pensar nuestra historia en términos políticos, luego la interpretamos a la luz de la economía y las relaciones de producción. Ahora, siguiendo su propuesta, tenemos que construirla en términos culturales.

Como nos lo sugiere el apartado anterior, al darle un mayor peso a las relaciones intersubjetivas, desde un principio hemos optado por la tercera vía. No obstante, a pesar de nuestra apuesta cultural, resulta importante no desvincularnos tajantemente de la postura estructural. Siguiendo lo dicho por Heller (1977:347), saber algo en la vida cotidiana significa apropiarse de las opiniones presentes, incorporando lo que se dice sobre ello a la experiencia personal. En este sentido, las ciencias sociales divulgan sus resultados introduciéndolos en la conciencia cotidiana; por lo que, en este mismo orden, la alusión espontánea a términos y conceptos como la urbanización, la industrialización, la migración campo-ciudad y el avance de la mancha urbana, entre otros, pueden hacer parte del discurso cotidiano, al ser estos incorporados e interpretados como parte de la experiencia subjetiva.

Una vez aclarado lo anterior, y atendiendo a un animo de integración, daremos lugar a la otra manera de concebir el problema.

\subsection{Urbanización, industrialización y expansión de la ciudad}

La urbanización en América Latina ha sido inducida por un modelo de desarrollo que privilegió la industrialización como sinónimo de progreso, desarrollo y modernidad. Asociando la ruralidad con esquemas premodernos y atrasados de desarrollo, se impusieron visiones de largo plazo que concebían a las sociedades latinoamericanas como sociedades modernas y urbanas. Tras este propósito se generaron procesos y se indujeron comportamientos poblacionales de índole económico y de índole social, coincidentes en el desestímulo al ámbito rural en beneficio del orden urbano.

Al respecto, Echeverri y Ribero (2002:37-39) nos hacen una buena síntesis de los principales factores que indujeron el proceso de urbanización:

a) Modelo sustitutivo e industrialización. Desde el final de la primera mitad del siglo XX, con la aplicación generalizada del modelo de sustitución de importaciones que cerraba la economía, se dio vía libre a la aplicación de esquemas orientados a la construcción de centros urbanos y de desarrollo industrial. Se permitió la creación de estructuras con incentivos asimétricos entre los sectores básicos de la economía rural (agropecuario y extractivo) frente a los nuevos sectores industriales de carácter urbano. Esta asimetría generó términos de intercambio desiguales que facilitaron flujos intensos de recursos humanos de las zonas rurales hacia las zonas urbanas.

b) Asimetrías macroeconómicas. La política macroeconómica aplicada durante estos periodos implicó el denominado impuesto agrario, producto de políticas cambiarias, tributarias, comerciales, fiscales, de recaudo y de inversión, que evidentemente desestimularon la inversión en el sector rural y lograron que los flujos excedentes y la acumulación rural se movilizaran hacia el medio urbano, financiando de esta forma la construcción de las grandes urbes de América Latina.

c) Incentivos a flujos de capitales. Todo este conjunto de políticas implicó fuertes incentivos a las inversiones urbanas, generando un enorme diferencial de rentabilidad entre el medio urbano y el medio rural. Inclusive los excedentes generados en el medio rural fueron destinados a inversiones en el medio urbano (industria o de servicios). Esto significó una descapitalización del medio rural a favor de los medios urbanos. 
d) Venta de un imaginario colectivo. Más allá de los instrumentos de orden económico y de la visión de planificación económica de todo el sistema de inversiones y desarrollo sectorial, se vendió la idea única de progreso asociado con el medio urbano. Se generalizó la idea de que el campo era una visión premoderna que condenaba al atraso a la sociedad. Se constituyeron valores y discursos ideológicos en contra del medio rural, que no solo tuvieron cabida en el naciente medio urbano, sino también en los mismos medios rurales, dando lugar a una idea generalizada de que el progreso y el bienestar se obtenían exclusivamente en la decisión de emigración hacia una zona urbana. Esta concepción de desarrollo único tuvo acogida generalizada y aún hoy prevalece limitando en forma importante el potencial de desarrollo del medio rural. El papel de los medios masivos de comunicación fue significativo en la venta de éste imaginario colectivo. No obstante, es necesario anotar que, pese a su protagonismo, las políticas oficiales no fueron la única vía. Alternamente, la influencia de los partidos de izquierda, con la afirmación de que sólo el proletariado era portador del cambio revolucionario, contribuyó a lo mismo.

e) Modelos de recurso humano. Uno de los instrumentos más importantes de presión migratoria lo constituyó la educación con modelos curriculares y pedagógicos que buscaban preparar e incentivar el traslado de la población hacia el medio urbano. En general el modelo de desarrollo de talento humano se concibió para alimentar mercados urbanos, y por lo tanto debilitó y subestimó las potencialidades económicas y sociales del medio rural, al mismo tiempo que privó a la población campesina de la formación específica y especializada que requería su desarrollo.

f) Expulsión y desplazamiento. La visión de desarrollo agropecuario, que se implementó asociada al modelo de urbanización, giró alrededor del modelo tecnológico de la revolución verde, intensivo en el uso de agroquímicos y maquinaria (es decir, intensivo en capital), que perseguía incrementos de productividad en las actividades primarias y se soportaba en un uso menor de mano de obra y una mayor tecnificación. Este modelo de economía agrícola comercial implicó un debilitamiento en las estructuras y sistemas productivos rurales basados en el uso intensivo de mano de obra y generó, naturalmente, una expulsión de población. De otro lado, la precariedad y el pobre éxito de procesos generalizados de reforma agraria y redistribución de la tierra, acompañados de procesos violentos de expulsión de la población, generaron desarraigos y desplazamientos masivos de población del medio rural al medio urbano.

Podemos plantear que la forma como se han dado los procesos históricos de construcción del sistema urbano o de concentración de población en los países de América Latina, caracterizado por el muy acelerado proceso de urbanización, trae como consecuencia una fuerte presencia de sociedades, culturas, tradiciones e instituciones rurales en las ciudades y en los medios urbanos del continente.

De acuerdo a Echeverri y Ribero (2002:40), un elemento básico destacable de esta herencia de condiciones rurales en el medio urbano, es la naturaleza y el origen rural de la pobreza urbana. En una altísima proporción, las grandes ciudades de nuestros países albergan un acumulado de pobreza rural, de inmigrantes rurales que no han encontrado soluciones y condiciones de desarrollo integral y que constituyen espacios de pobladores rurales incrustados en la ciudad, con bajos niveles de integración al mundo urbano y con grandes nexos con el medio rural.

En esta misma vía, podemos plantear que las grandes ciudades de nuestra América Latina son ciudades de un profundo sincretismo y complejidad de orden cultural y social que mimetiza, en grandes conglomerados urbanos, poblaciones de profundo sustrato rural. Definitivamente, esta relación y esta mixtura en los grandes centros metropolitanos con sustrato cultural, social e institucional rural, son, al tiempo que paradoja, una gran limitación y un gran desafío para el desarrollo de nuestros países. 
No obstante, a todo lo anterior hay que sumar algo más. Como hemos planteado hasta el momento, la articulación entre lo rural y lo urbano puede ser interpretada como una causa de la rápida urbanización. Pero, si se trata de la expansión de la urbe, ¿sobre qué sustrato físico se extiende ésta? 


\subsection{Urbanización física del espacio rural}

Una de las funciones urbanas más importantes es la de suministrar vivienda a quienes habitan la ciudad, bien sea de forma transitoria o permanente. Sin embargo, la ciudad en muchas ocasiones no puede responder de una manera eficiente a esta demanda.

Ante el bajo poder adquisitivo de los estratos bajos, surgen las llamadas soluciones informales o asentamientos subnormales. Según Gutiérrez (1998), se trata de invasiones o de las llamadas urbanizaciones piratas, organizadas generalmente por un empresario particular que especula con tierras localizadas fuera del perímetro sanitario, algunas de alta peligrosidad por su erosionabilidad o inundabilidad o que no cumplen con las normas y planes previstos para la ciudad, y, por tanto, no cuentan con obras de infraestructura. Estas tierras se dividen en lotes que son adquiridos para edificar por autoconstrucción y hoy constituyen parte considerable de las grandes ciudades, fenómeno que las deforma al orientar su expansión sobre áreas inadecuadas.

Pero, ¿qué tiene que ver la situación descrita con el ámbito rural? Es importante considerar que la expansión de la mancha urbana no siempre se produce sobre zonas baldías. También se hace sobre zonas que, aunque no están totalmente habitadas, están destinadas a la producción agrícola. Es más, aunque no se produzca una invasión directa, la simple vecindad o cercanía con espacios urbanizados representa problemas para los habitantes rurales. La contaminación de las aguas debido a la descarga de residuos de diversa índole, la extracción de recursos destinados a atender las necesidades de los vecinos urbanos, la inseguridad, entre otros, son situaciones que resultan problemáticas.

Siguiendo a Erviti (1989:57), la concentración en la periferia de las ciudades en los países denominados en vía de desarrollo tiene las siguientes características:

a) Ausencia o precariedad de títulos legales sobre la tierra.

b) Precariedad y ausencias de condiciones sanitarias y de bienestar.

c) Altas densidades humanas, traducidas en hacinamiento, como consecuencia de la relación negativa entre espacio habitable y número de habitantes.

d) Marginalidad social, acentuada por la pobreza en que se vive.

Esta caracterización, a pesar de haber sido originada a finales de los ochenta, aun conserva su vigencia. Las precarias condiciones de vida de muchos individuos que habitan las ciudades se ven agudizadas en este tipo de asentamientos.

Ante esta situación, la urbanización marginal puede llegar a convertirse en la referencia más inmediata acerca de un posible futuro urbano. Constatar que no todos los habitantes de la ciudad tienen acceso a los servicios urbanos, puede contribuir a la revalorización de lo rural. Así, la imagen idealizada de progreso asociado al medio urbano empieza a perder peso.

No obstante, es importante considerar que la urbanización subnormal no es la única vía de expansión física de la ciudad sobre el espacio rural. Como ya hemos anotado al referirnos a las nuevas funciones urbanas de lo rural, la conservación del medio natural como estrategia de recuperación y conservación del equilibrio urbano promueve el cambio del uso del suelo. Al declararse zonas rurales como de conservación, en beneficio de la contraparte urbana, en muchas ocasiones se pasa por alto que estas son áreas vitales para el sostenimiento de las familias dedicadas a la producción agrícola. En estos casos, aunque no hay edificación, nos encontramos ante un proceso de urbanización del uso del suelo, fenómeno que marca el tránsito de lo urbano a lo rural. 
A manera de ilustración Linck (2002:1) nos describe el caso específico de la Ciudad de México:

"De los años 1930 en adelante, cuando la ciudad de México alcanza el millón de habitantes, el crecimiento urbano ha experimentado franco aceleramiento. Hoy en día, con una población que se acerca a los diecinueve millones de habitantes (área metropolitana), las áreas rurales han disminuido en un grado preocupante. Hacia el sur del Distrito Federal, donde se observa el mayor crecimiento poblacional, este se reduce a un conjunto heterogéneo de tierras pantanosas convertidas en baldios, basureros, áreas de chinampas amenazadas por el hundimiento. De los años 60 en adelante, esta función de reserva tradicional cobra el sentido de santuario. Se han implementado vedas, restricciones a las construcciones y al uso del suelo, programas de reforestación. La especulación relacionada con las grandes empresas inmobiliarias se han reducido, cobrando auge la multiplicación de los asentamientos irregulares. En la década de los 80 y los 90, las delegaciones del sur de la ciudad siguen ostentando un elevado índice de crecimiento. La definición de una política eficiente de contención de la mancha urbana sigue siendo una preocupación prioritaria”.

En síntesis, podemos plantear que la urbanización física del espacio rural es otra forma de interacción entre lo rural y lo urbano. De esta manera, los problemas urbanos pasan a ser también competencia del ámbito rural, situación que, de igual forma, contribuye al desdibujamiento de los límites entre estas dos categorías.

\section{Consideraciones finales}

Dentro de la nueva concepción de lo rural, la articulación con lo urbano ocupa un lugar preponderante. Al momento de plantear la discusión, el desdibujamiento de los límites entre estas dos categorías tradicionalmente expuestas como antagónicas, constituye uno de los principales puntos de análisis. En términos generales, la discusión se fundamenta en el supuesto, según el cual, el ritmo de las transformaciones sociales ha modificado las nociones de lo urbano y lo rural, en categorías simbólicas que no corresponde más a realidades culturales y socialmente distintas, tornándose cada vez más difícil delimitar fronteras claras entre las ciudades y las áreas rurales circundantes, las cuales se funden en un entramado cada vez más indiferenciable.

No obstante, es importante considerar que lo rural no está pasando por un proceso único de transformación en toda su extensión, y que, en este sentido, es difícil hablar de nueva ruralidad en general, pues ella se expresa de forma diferente en universos culturales, sociales y económicos heterogéneos. Problematizando lo anterior, podemos plantear que el estrechamiento de los lazos entre lo urbano y lo rural puede tomar varios matices.

De esta manera, la relación entre las partes puede oscilar entre la armonía y el conflicto. Así, la cercanía física entre la ciudad y el campo puede ser entendida como una oportunidad, pero a su vez, también, como una amenaza. En la medida en que el acercamiento facilita las relaciones comerciales, la incursión en el mercado de trabajo-no agrícola y el acceso a servicios de infraestructura social, entre otras formas de articulación, el desvanecimiento de la frontera entre lo urbano y lo rural, puede ser interpretado como una oportunidad. Sin embargo, en la medida en que de la articulación se pasa a la absorción física de lo rural por lo urbano, la relación puede tornarse ampliamente conflictiva, volcando ahora la atención sobre la defensa del territorio. 
De acuerdo al planteamiento de Karl Jasper (1997), es debido a la inconformidad con la verdad que poseemos en determinado momento, que siempre queremos e iniciamos la búsqueda de una verdad más completa, de una verdad que supere la anterior. Para este caso, la inconformidad con un concepto de nueva ruralidad que sólo aborda las relaciones entre lo urbano y lo rural desde una perspectiva armónica, es decir, desde lo funcional, constituye el punto de partida. Aquí se considera que la exclusión de las nuevas relaciones conflictivas entre las partes hacen incompletas las nociones actuales.

Es precisamente de esta inconformidad de donde deriva la necesidad de abordar el problema desde un ángulo distinto. Es a través de la complementación temática que la verdad entretejida en torno al problema que nos ocupa podrá llegar a perfeccionarse y, en las palabras de Jasper, a trascender.

En este mismo sentido, atender al perspectivismo expuesto por Ortega y Gasset (1997) resulta evidentemente apropiado: ¿Desde qué perspectiva aprehendemos las relaciones entre lo rural y lo urbano? En la medida en que se haga desde distintos ángulos podríamos llegar a una versión más completa, lograda a través de la suma de complementariedades.

De acuerdo a este mismo autor, todos tenemos en la práctica cierta perspectiva de la realidad dependiente de diversos factores, por ejemplo, de nuestra ubicación espacial, de nuestra cultura, de nuestro tipo de formación, etc. De esta manera, dependiendo de nuestro punto de mira podemos interesarnos en algunas cosas, mientras que otras pueden pasar desapercibidas. Pero, ¿de qué cosas se interesan quienes experimentan el problema en su vida diaria?

Zubiri (1997) plantea que en la vida cotidiana nunca nos preguntamos si algo es o no real, en primera instancia aceptamos el mundo como es, como lo percibimos, siendo la verdad aquello que nos llega, siendo la verdad una verdad sentiente.

Acogiendo lo anterior, para que una nueva noción de lo rural avance hacia la integralidad ha de incorporar, en esencia, todo aquello que los actores rurales asumen como verdad, es decir, lo que sienten, lo que perciben, lo que simplemente experimentan en su quehacer cotidiano. En este sentido, las relaciones entre lo rural y lo urbano no pueden reducirse a conjeturas al margen de lo que experimentan los seres en su vida diaria. La categorización y la tipificación de sus acciones no es algo suficiente. Es necesario trascender ese estado de entendimiento del fenómeno, para entrar a comprenderlo desde un estado más básico, más ajustado a los sentidos.

Pero, ¿cómo incorporar la observación de los sujetos directos de la acción? En otras palabras, ¿cómo incorporar la visión de quienes experimentan el fenómeno en su diario acontecer?

Tal y como plantea Gadamer (1992), conversando es como nos entendemos. Muchas veces malentendiéndonos, pero al fin y al cabo utilizando las palabras que nos hacen compartir un mismo mundo. Aunque cada uno tiene su propio lenguaje, no existe el problema de la necesidad de un lenguaje común para todos. Según este autor, el modo de ser de las cosas se nos revela hablando de ellas. Las cosas se nos presentan como una realidad común cuando hablamos de ellas.

No obstante, a pesar de nuestro intento por entender al otro, la realidad continúa siendo un fenómeno extremadamente complejo. Nuestros sentidos nos permiten aprenderla solo en algunos de sus aspectos. De esta manera, los límites de la comprensión de la realidad comienzan por nuestra propia percepción de ella.

En esta vía, la forma que escogemos para representar la realidad no depende exclusivamente de la forma como la observamos organizada, sino también de como la organizamos, siendo este ensayo una muestra de 
ello, es decir, una manera, entre tantas posibles, de aproximarnos a las relaciones entre lo rural y lo urbano. Así, las nociones usadas para entender la realidad parten de las representaciones y de los conceptos pre-existentes. En este sentido, con dificultad hablaríamos de la articulación entre lo urbano y lo rural, si antes la sociología rural no hubiera incorporado a su cuerpo teórico los conceptos derivados de teorías como la del continuo rural-urbano o los de la dependencia. Igualmente, si las antiguas teorías no hubiesen sido polemizadas con anterioridad, con dificultad podríamos envestirlas con nuevos conceptos y significaciones.

Para terminar vale mencionar que el concepto de rural, como muchos otros, es simultáneamente suficiente e insuficiente. La realidad no conoce clasificaciones o esquemas: nosotros los creamos para orientarnos en la complejidad de la existencia, la cual necesitamos conocer, sea a través de teorías científicas o de sentido común. Para organizar nuestra experiencia amoldamos la realidad de diferentes formas.

Igualmente, debido a las características peculiares de nuestro ramo de conocimiento, en las ciencias sociales probablemente jamás habrá consenso acerca del concepto de lo rural. De esta manera, cada vez que emprendamos un trabajo que involucre este concepto es prudente explicitar claramente en que sentido es entendido y a cuáles fenómenos y aspectos de la realidad se refiere.

\section{Bibliografía}

BEJARANO, JESÚS. 1998. "El concepto de lo rural: ¿qué hay de nuevo?" Revista Nacional de Agricultura. Nos 922-923. Bogotá. Colombia.

BERGER, PETER Y LUCKMANN, THOMAS. 1979. La construcción social de la realidad. Amorrortu Editores. Buenos Aires. Argentina.

CARNEIRO, MARIA JOSÉ. 2000. Ruralidade: novas identidades en construção. Projeto Rurbano. Instituto de Economía. Universidade de Campinas. Disponible en:

http://www.eco.unicamp.br/nea/rurbano/textos/downlo/rurbzeze.html [Fecha de acceso: 22-08-2003].

CEÑA, FELISA. 1993. "El desarrollo rural en sentido amplio". En: El desarrollo rural andaluz a las puertas del siglo XXI. Congresos y Jornadas. No 32/93. Consejería de Agricultura y Pesca. Andalucía. España.

CRUZ, MARIA SOLEDAD Y MORENO, ALEJANDRA. 2002. "Areas rurales, recursos naturales y ordenamiento urbano". En: Revista Ciudades. Abril-Junio. Puebla. México.

DA SILVA, JOSÉ. 1997. A nova rural brasileiro. Projeto Rurbano. Instituto de Economía. Universidade de Campinas. Brasil. Disponible en:

http://www.eco.unicamp.br/nea/rurbano/textos/congrsem/rurbano7.html [Fecha de acceso: 22-08-2003].

DEL ROBLE, MARIO. 2001. "El desafío rural del siglo XXI para el Distrito Federal". En: Estudios Agrarios. No 16. Procuraduría Agraria. México.

ECHEVERRI, RAFAEL. 1998. Colombia en transición. De la crisis a la convivencia: una visión desde lo rural. Misión Rural-IICA-FINAGRO. Tercer Mundo Editores. Bogotá.

ECHEVERRI, RAFAEL Y RIBERO, MARÍA PILAR. 2002. Nueva ruralidad. Visión del territorio en América Latina y el Caribe. IICA. CIDER. Corporación Interamericana Misión Rural. Bogotá.

ERVITI, BEATRIZ. 1989. La urbanización de América Latina: interpretación histórica, niveles y patrones actuales y diferencias regionales. Centros de Estudios Demográficos. Universidad de La Habana. Cuba.

GADAMER, HANS-GEORG. 1992. Verdad y método. Ediciones Salamanca. España.

GALSTON, W. Y BAEHLER, K. 1995. Rural Development. Connecting theory, practice and possibilities. Islan Press. Washington, D.C.

GUTIÉRREZ, NIDIA. 1988. El proceso de urbanización en Colombia como producción social de formas especiales. Centro de Recursos Educativos. Universidad Piloto de Colombia. Bogotá. 
HENAO, GLORIA. 1991. "Reflexiones sobre la persistencia de lo rural en la ciudad". En: El campesinado en Colombia hoy. Pontificia Universidad Javeriana. Facultad de Ciencias Económicas y Administrativas. Ecoe Ediciones. Bogotá.

JASPER, KARL. 1998. "De la verdad". En: Teorías de la verdad en el siglo XXI. Juan Antonio Nicolás y Maria José Frápolli (editores). Editorial Tecnos. Madrid.

JIMÉNEZ, CARLOS. 1998. "Lo rural y lo urbano: una reflexión en torno a su definición”. En: Avances de Investigación. Departamento de Sociología Rural. Universidad Autónoma Chapingo.

KAGEYAMA, ANGELA. 1998. "Pluriatividade e ruradiladade: aspectos metodológicos". En: Economia Aplicada. Vol 2. No 3. Departamento de Economia. Faculdade de Economia, Administração e Contabilidade. Universidade de São Paulo. Brasil.

LINCK, THIERRY. 2000. El campo en la ciudad: reflexiones en torno a las ruralidades emergentes. Ponencia. Seminario Internacional. La Nueva Ruralidad en América Latina. Maestría en Desarrollo Rural. Facultad de Estudios Ambientales y Rurales. Pontificia Universidad Javeriana. Bogotá.

LINCK, THIERRY. 2002. Entre autonomía y patrimonialización de los territorios rurales del Distrito Federal.

MATTEI, LAURO. 1998. Pluriactividade e desenvolvimento rural no Estado de Santa Catarina. Teses de Doutorado. Instituto de Economia. Universidade de Campinas. Brasil.

NEWBY, HOWARD Y SEVILLA-GUZMÁN, EDUARDO. 1983. Introducción a la sociología rural. Editorial Alianza Universidad. Madrid.

ORTEGA Y GASSET, JOSÉ. 1997. “¿A qué llamamos verdad?” En: Teorías de la verdad en el siglo XXI. Juan Antonio Nicolás y Maria José Frápolli (editores). Editorial Tecnos. Madrid.

PANIAGUA, ALBERTO. 1998. "Criterios y procedimientos para identificar espacios rurales capaces de articularse positivamente a ciudades intermedias". Revista Políticas Agrícolas. Número Especial. Pag 243268.

PICKENHAYN, JORGE. 1982. Género de vida y hábitat rural y urbano. Facultad de Filosofía, Humanidades y Artes. Universidad Nacional de San Juan. Argentina.

RAMÍREZ, BLANCA Y ARIAS, PATRICIA. 2002. "Hacia una nueva rusticidad". Revista Ciudades. Abril-Junio. Puebla. México

RAMOS, EDUARDO Y ROMERO, JUAN. 1993. "La crisis del modelo de crecimiento y las nuevas funciones del mundo rural". En: El desarrollo rural andaluz a las puertas del siglo XXI. Congresos y Jornadas. No 32/93. Consejería de Agricultura y Pesca. Andalucía. España.

RELLO, FERNADO. 1998. "La ciudad intermedia, un factor del desarrollo regional". Revista Políticas Agrícolas. Número Especial. El caso de Zamora, México. Pag 227-242.

RODRÍGUEZ, ROMÁN. 1997. La Urbanización del espacio rural en Galicia. Concello de Lalin. Editorial Oikos-Tau. Barcelona. España.

SACCO DOS ANJOS, FLAVIO. 1995. Agricultura familiar, pluriactividad y desarrollo rural en el sur de Brasil. Tesis Doctoral. Instituto de Economía. Universidad de Campinas. Brasil.

SANTOS, MILTON. 1996. Metamorfosis del espacio habitado. Oikos-tau. Madrid.

SCHNEIDER, SERGIO. 2001. Elementos teóricos para análise da pluriatividade en situaçoes de agricultura familiar. II Seminário sobre o novo rural brasilero. Instituto de Economía. Universidade de Campinas. Brasil. Disponible en:

http://www.eco.unicamp.br/nea/rurbano/textos/congrsem/iisemina/sergio.htm [Fecha de acceso: 22-082003].

SIQUIERA, DIES Y OSORIO, RAFAEL. 2000. “O conceito de rural”. En: ¿Una nueva ruralidad en América Latina? Colección Grupos de Trabajo. CLACSO. Buenos Aires.

SOROKIN Y ZIMMERMANN. 1929. Principles of rural-urban sociology. Henrry Holt. New York.

ZUBIRI, XAVIER. 1997. "La realidad en la intelección sentiente: la verdad real". En: Teorías de la verdad en el siglo XXI. Juan Antonio Nicolás y Maria José Frápolli (editores). Editorial Tecnos. Madrid. Pag. 385-396. 